\title{
ICRF HEATING AND TRANSPORT OF DEUTERIUM-TRITIUM PLASMAS IN TFTR
}

\author{
M. Murakami ${ }^{\dagger}$, E.F. Jaeger ${ }^{\dagger}$, R. Majeski, C.K. Phillips, D.A. Rasmussen ${ }^{\dagger}$, J.H. Rogers, G. Schilling, \\ J.E Stevens, G. Taylor, C.Y. Wang $\S$, J.R. Wilson, D.B. Batchelor ${ }^{\dagger}$, M.G. Bell, R.V. Budny, C.E. Bush $\dagger$, \\ N.L. Bretz, D. Darrow, A.C. England ${ }^{\dagger}$, E. Fredrickson, R. Goldfinger ${ }^{\dagger}$, G. Hammett, G.R. Hanson ${ }^{\dagger}$, \\ J.C. Hosea, H.K. Park, S.D. Scott, E. Synakowski, R.M. Wieland, J.B. Wilgen ${ }^{\dagger}$, and M.C. Zarnstorff \\ Princeton Plasma Physics Laboratory \\ P. O. Box 451, \\ Princeton, New Jersey 08543
}

\section{ABSTRACT}

This paper describes results of the first experiments utilizing high-power ion cyclotron range of frequency (ICRF) to heat deuterium-tritium (D-T) plasmas in reactor-relevant regimes on the Tokamak Fusion Test Reactor (TFTR). Results from these experiments have demonstrated efficient core, second harmonic, tritium heating of D-T supershot plasmas with tritium concentrations ranging from $6 \%-40 \%$. Significant direct ion heating on the order of $60 \%$ of the input radio frequency ( $\mathrm{f} f$ ) power has been observed. The measured deposition profiles are in good agreement with twodimensional modeling code predictions. Energy confinement in an rf-heated supershot is at least similar to that without $\mathrm{rf}$, and possibly better in the electron channel. Efficient electron heating via mode conversion of fast waves to ion Bernstein waves (IBW) has been demonstrated in ohmic, deuterium-deuterium and DTneutral beam injection plasmas with high concentrations of minority ${ }^{3} \mathrm{He}\left(\mathrm{n}_{3} \mathrm{He} / \mathrm{n}_{\mathrm{e}}=15 \%-30 \%\right)$. By changing the ${ }^{3} \mathrm{He}$ concentration or the toroidal field strength, the location of the mode-conversion radius was varied. The power deposition profile measured with rf power modulation indicated that up to $70 \%$ of the power can be deposited on electrons at an off-axis position. Preliminary results with up to $4 \mathrm{MW}$ coupled into the plasma by 90 degree phased antennas showed directional propagation of the mode-converted IBW. Analysis of heat wave propagation showed no strong inward thermal pinch in off-axis heating of an ohmically-heated target plasma in TFTR.

\section{INTRODUCTION}

Future fusion devices, such as the International Thermonuclear Experimental Reactor (ITER), emphasize ion cyclotron range of frequency (ICRF) heating and cur-

\footnotetext{
tOak Ridge National Laboratory, P. O. Box 2009, Oak Ridge, Tennessee 37831-8072 USA

$\S$ Oak Ridge Associated Universities
}

rent drive (CD). Tritium second harmonic cyclotron resonance $(2 \Omega \mathrm{T})$ is the proposed heating scenario in ITER operation, but until now, no experimental data have been available. The Tokamak Fusion Test Reactor (TFIR) has performed the first experiments on ICRF heating of D-T plasmas showing significant ion heating in the $2 \Omega \mathrm{T}$ regime. ${ }^{[1,2]}$ An increasing emphasis is being placed on control of the plasma current profile in order to access the Advanced Tokamak operating regime in future devices, such as the Tokamak Physics Experiment (TPX). Mode conversion to ion Bernstein waves (IBW) has been proposed for the profile control, and, in particular, off-axis heating and $C D$. The efficient mode conversion scheme recently proposed ${ }^{[3]}$ has been demonstrated for the first time in TFTR in ${ }^{3} \mathrm{He}-{ }^{4} \mathrm{He}$ plasmas. [4] Benchmarking of the if computer codes, which are needed for designing future devices, with these experimental data has been facilitated by $\mathrm{rf}$ power modulation.

This paper gives an overview of the recent TFTR ICRF experiments. Section II describes ICRF heating in D-T plasmas, demonstrating second harmonic tritium heating, the benchmarking of rf modeling, and comparison of confinement of rf-heated D-T supershots with those heated by neutral beam injection (NBI) alone. Section III describes experiments on mode conversion of fast waves to IBWs, demonstrating the efficient on- and off-axis mode conversion, and testing for an inward thermal pinch by the use of off-axis heating. Section IV conclude the discussion with future plans.

\section{ICRF HEATING IN D-T PLASMAS}

The initial series of ICRF heating experiments with D-T plasmas had two main experimental objectives: to investigate the physics of ICRF-heated plasmas in the $2 \Omega_{T}$ regime and to enhance the performance of D-T supershots. Plasma reactivity can be increased by directly heating tritium ions via second harmonic ICRF. Significant increases in the central electron heating of supershots via direct electron heating or collisional heating with minority tail ions may result in the lengthening of the alpha particle slowing time and an 
enhancement of the alpha particle pressure in D-T plasmas, facilitating the investigation of alpha-particle effects in TFTR. Transport in these rf-heated D-T discharges is of significant interest.

A total of 21 D-T supershot target plasmas driven by 18 to $24 \mathrm{MW}$ of $\approx 100-\mathrm{keV}$ NBI were heated with ICRF power launched by up to four antennas located at the midplane on the low-field side of the torus. ${ }^{[5]}$ Input power of up to $5.8 \mathrm{MW}$ was coupled to full-size (major radius, $R_{0}$, of $2.62 \mathrm{~m}$, and minor radius, $a_{\text {, of }} 0.96 \mathrm{~m}$ ) D-T plasmas at an rf frequency of $43 \mathrm{MHz}$ with out-of-phase current -strap excitation. To elucidate heating mechanisms, two systematic scans were conducted: (1) a tritium concentration scan with $\eta_{\mathrm{T}}\left(\equiv \mathrm{n}_{\mathrm{T}} / \mathrm{n}_{\mathrm{e}}\right)$ ranging from $6 \%-40 \%$ by varying the ratio of injected tritium to deuterium neutral beams, and (2) a toroidal field scan to vary the location of the $2 \Omega_{\mathrm{T}}$ layer relative to the magnetic axis.

The if power modulation provides a technique for directly measuring the ICRF power absorption profiles by examining the time response of the measured ion- and electron-stored energies to the if power modulation. $[6,7]$ The electron and ion heating power per unit volume can be inferred from either: (1) the change in the time-derivative of the electron and ion energy density when the if power was turned on or off, or (2) the Fourier transform analysis carried out over several cycles of modulation. The electron-stored energy was computed from the electron temperature profile, measured by electron cyclotron emission (ECE), combined with the electron density profile, obtained by a multi-channel far infrared interferometer (MIRI). The ion stored energy was computed from the charge exchange recombination spectroscopy (CHERS) measurement of $T_{i}$ combined with the thermal ion density calculated by the TRANSP code

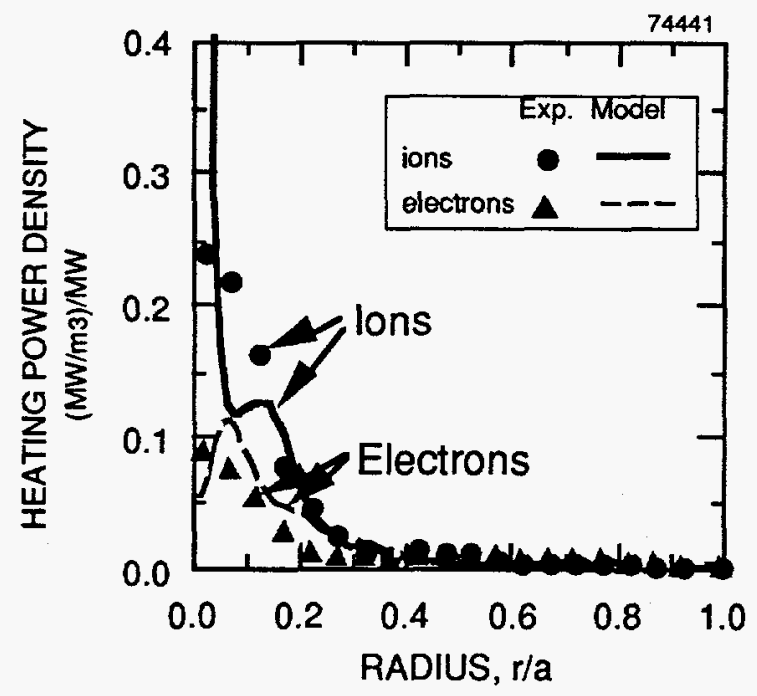

Fig. 1. Ion and electron heating power density as a function of radius measured (solid circles and triangles) with the modulation technique with the $2 \Omega_{\mathrm{T}}$ layer on the magnetic axis with $60 \%$ tritium NBI. The continuous curves are the heating power density profiles predicted by the PICES code. which was in turn based on the electron density, $Z_{\text {eff }}$ (obtained from visible bremstrahlung) and a Monte Carlo beam deposition model. Figure 1 shows the local ion and electron power deposition profiles (for a 1-MW power input to the antenna) obtained from the modulation analysis for a plasma where the $2 \Omega_{\mathrm{T}}$ layer was located at the magnetic axis and with $60 \%$ tritium NBI $\left[\mathrm{B}_{\mathrm{T}}=4.6 \mathrm{~T}\right.$, $\left.R_{a x i s}=2.82 \mathrm{~m}, \mathrm{P}_{\mathrm{bT}} /\left(\mathrm{P}_{\mathrm{bD}}+\mathrm{P}_{\mathrm{bT}}\right)=0.6\right]$. The central portion of the ion and electron local power deposition profiles can be expressed as Gaussians, $\exp \left[-(\rho / \alpha)^{2}\right]$, with $\alpha=0.17$ and 0.16 , respectively, where $\rho$ is the normalized minor radius $\mathbf{r} / \mathrm{a}$. The volume integrated values of the curves give the power absorption (within $\mathrm{r}=$ a with uncertainties in the analysis) of $59 \pm 10 \%$ for ions and $26 \pm 3 \%$ for electrons. The total absorption, $85 \pm$ $10 \%$, is consistent with the value, $80 \pm 10 \%$, estimated by magnetic analysis.

The of modeling predictions compare favorably with the experimental results determined by if modulation. The curves overlaying the experimental points in Figure 1 are the ion and electron heating power deposition profiles predicted by the PICES code. [8] PICES is a two-dimensional (2-D), reduced-order, full wave code, with multiple (80) toroidal modes for representation of the launched antenna spectrum. The PICES analysis is based on the experimental temperature and density profiles (including beam ions with an effective temperature of $\sim 60 \mathrm{keV}$ on axis). The calculated heating power density profiles are similar to the experimental measurements. Of the total if power, $26 \%$ was absorbed directly by electrons via Landau damping and transit time magnetic pumping near the core, in good agreement with rf modulation data. Of the $49 \%$ ion absorption, $43 \%$ was absorbed at the $2 \Omega \mathrm{T}$ resonance in the core and $6 \%$ near the $\mathrm{D}$ (and carbon) fundamental resonance located at $r / a \approx 0.7$. This code also predicts that $\sim 16 \%$ of the rf power was absorbed at the intersection of deuterium ion fundamental resonance $(\mathrm{R} \approx 2.1 \mathrm{~m})$ and the mode conversion layer near the last closed flux surface. So far there is no experimental evidence to support (or refute) this effect. Power deposition profiles were also calculated for the same plasma with the rf package in TRANSP, consisting of a 2-D reduced-order wave solver, SPRUCE, [9] combined with the bounceaveraged Fokker-Planck solver, FPP. [10] From this analysis, $24 \%$ of the power was absorbed by electrons and $63 \%$ by ions within $\mathrm{r} / \mathrm{a}=0.85$. The differences between the results of PICES and TRANSP stem primarily from the difference in the multiple and single mode calculations. The power splits predicted by both codes are in relatively close agreement with the data.

Similar agreement between the experimental power splits and the model predictions are found for the data from the tritium concentration scan with the $2 \Omega_{\mathrm{T}}$ layer on axis, as shown in Figure 2. The observed trends in the data are consistent with the theoretical prediction that the 


\section{DISCLAIMER}

This report was prepared as an account of work sponsored by an agency of the United States Government. Neither the United States Government nor any agency thereof, nor any of their employees, make any warranty, express or implied, or assumes any legal liability or responsibility for the accuracy, completeness, or usefulness of any information, apparatus, product, or process disclosed, or represents that its use would not infringe privately owned rights. Reference herein to any specific commercial product, process, or service by trade name, trademark, manufacturer, or otherwise does not necessarily constitute or imply its endorsement, recommendation, or favoring by the United States Government or any agency thereof. The views and opinions of authors expressed herein do not necessarily state or reflect those of the United States Government or any agency thereof. 


\section{DISCLAIMER}

Portions of this document may be illegible in electronic image products. Images are produced from the best available original document. 
$2 \Omega \mathrm{T}$ heating efficiency increases with the tritium beta. Up to $59 \pm 10 \%$ of the if power was observed to be

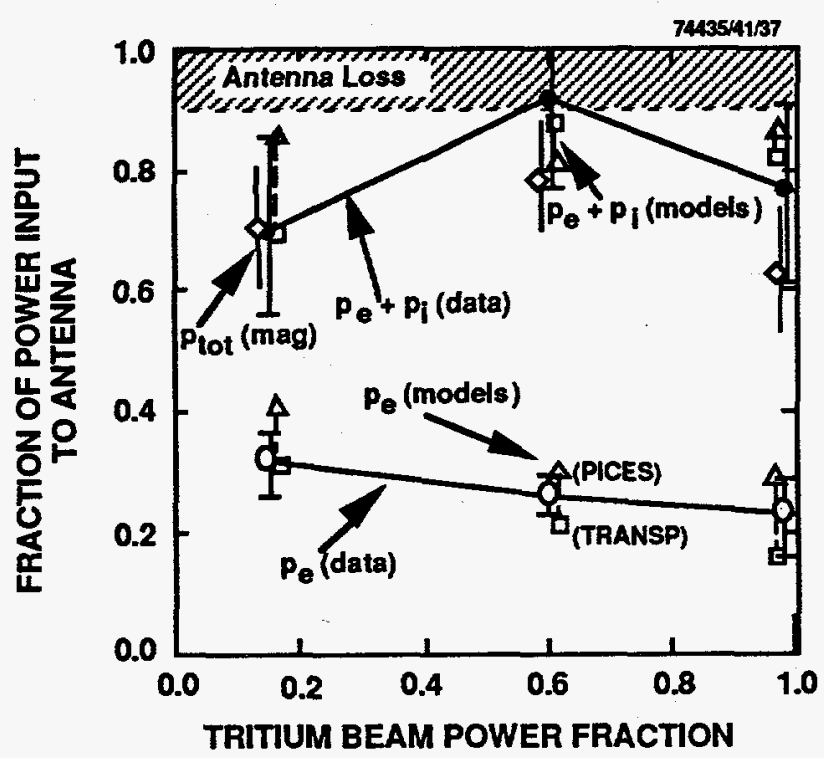

Fig. 2. Dependence of the measured power fraction absorbed directly by electrons and ions is shown as a function of tritium beam power fraction during if modulation. Also shown are the total absorbed power fraction (open diamonds) determined from the magnetic analysis, and the electron and ion power splits predicted by if modeling codes, PICES (open triangles) and TRANSP (open square).

absorbed by ions. The core $2 \Omega_{\mathrm{T}}$ heating is strong even for $\eta_{\mathrm{T}}$ as low as $\sim 6 \%$ (15\% of NBI power in $\mathrm{T}$ ) primarily due to the presence of hot tritium beam ions. Further experimental evidence supports the core $2 \Omega_{\mathrm{T}}$ absorption: (1) the $B_{T}$ scan showed that the ion heating peaks at the $2 \Omega_{\mathrm{T}}$ layer on axis, which is in agreement with the models ${ }^{[2]}$; and (2) the fast ion loss detectors observed escaping tritium tail ions (of $-600 \mathrm{keV}$ ) synchronously with if modulation. [11]

The addition of 5.8 MW of ICRF power to a D-T supershot resulted in a significant increase in the core ion and electron temperatures ${ }^{[1]}$, as shown in Figures $3 \mathrm{a}$ and 3b. A plasma line average density of about $4 \times 10^{19} \mathrm{~m}^{-3}$ was established by $\mathrm{NBI}$, and $2 \%{ }^{3} \mathrm{He}$ gas was added to minimize effects of $\mathrm{rf}$ eigenmode excitation. The $43-\mathrm{MHz}$ ICRF waves were resonant with both the minority ${ }^{3} \mathrm{He}\left(\omega \sim \Omega_{3 \mathrm{He}}\right)$ and the majority tritium $\left(\omega \sim 2 \Omega_{\mathrm{T}}\right)$ near the Shafranov-shifted magnetic axis $\left(\mathrm{B}_{\mathrm{T}}=4.2 \mathrm{~T}\right.$ at $\left.\mathrm{R}=2.83 \mathrm{~m}\right)$. The central ion temperature, measured by CHERS, increased from 26 to $36 \mathrm{keV}$. The central electron temperature, as measured by ECE, increased from 8 to $10.5 \mathrm{keV}$, due to a combination of direct electron heating via Landau damping and collisions with minority tail ions. There was also a $10 \%$ increase in the D-T neutron production rate to $\sim 1.2 \times 10^{18} \mathrm{~s}^{-1}$ during the early part of the discharge. However, the performance was spoiled by an enhanced carbon influx that began at about $3.4 \mathrm{~s}$ due to the plasma moving to an unconditioned portion of the limiter. Figures $3 c$ and $3 d$ show the measured ICRF heating power density added to the underlying heating power calculated for neutral beam, ohmic, and $\alpha$-particles to ions and electrons. The ICRF additions are significant out to $r / a \sim 0.3$, leading to the increase in $T_{i}$ and $T_{e}$ there. The observed core ion heating is consistent with $2 \Omega_{\mathrm{T}}$ heating, because an analogous increase was not evident in the earlier $\mathrm{D}\left({ }^{3} \mathrm{He}\right)$ experiments. ${ }^{[12]}$ Furthermore, a core ion temperature of $32 \mathrm{keV}$ was obtained with only 4.4 MW of ICRF power during a companion discharge that was essentially identical to the present case without ${ }^{3} \mathrm{He}$ added.

Measurements of the ion and electron and heating power density allow the examination of the effects of transport in rf-heated plasmas relative to that with NBI alone. Figures $3 \mathrm{e}$ and $3 \mathrm{f}$ show the total effective heat diffusivity for ions and electrons as a function of radius with the measured if power deposition profiles (rather than the predicted $\mathrm{rf}$ deposition profiles by the model) incorporated in the post-TRANSP analysis. To avoid prescribing a particular convective multiplier $(3 / 2$ or $5 / 2)$, the local transport is characterized by the total (conductive and convective) effective diffusivity $\chi_{i}^{\text {tot }}$ and $\chi_{e}^{\text {lot }}$ which are the ratio of the total radial ion and electron heat flux to the corresponding temperature gradient. The same conclusions, however, can be drawn from the usual ion and electron thermal diffusivity analysis. There is no significant difference between the $\chi_{i}^{\text {tot }}$ profile with and without $\mathrm{rf}$, indicating that $\mathrm{T}_{\mathrm{i}}(\mathrm{r})$ increases with $\mathrm{rf}$ power while maintaining $\chi_{i}$. Electron transport is even more favorable with $\mathrm{rf}$. It showed a reduction in $\chi_{e}^{\text {tox }}$ by almost factor of 2 in the radii outside $\rho=0.4$. So confinement of rf-heated D-T plasmas is at least similar to that with NBI alone, and possibly better in the electron channel. Inclusion of rf-driven ripple loss tends to indicate more favorable confinement for rf-heated shots. [13]

\section{MODE CONVERSION EXPERIMENTS}

Recently, a novel technique for localized electron heating and $\mathrm{CD}$ utilizing efficient mode conversion of fast magnetosonic waves into IBW at two-ion hybrid layers has been suggested by Majeski et al.[3] This technique is D-T compatible, uses no extra hardware, and may provide off-axis $C D$ to access the advanced tokamak operating regime. In contrast to mode conversion ${ }^{[14]}$ in the conventional minority heating scheme utilizing a small minority ion concentration, the proposed scheme enhances the mode conversion efficiency (and thereby the electron heating efficiency) by: (1) separating the mode conversion layer (at the two-ion hybrid layer $n / /^{2}=S$ ) from the cyclotron layer; and (2) forming a closely spaced "cutoffresonance-cutoff" triplet. 

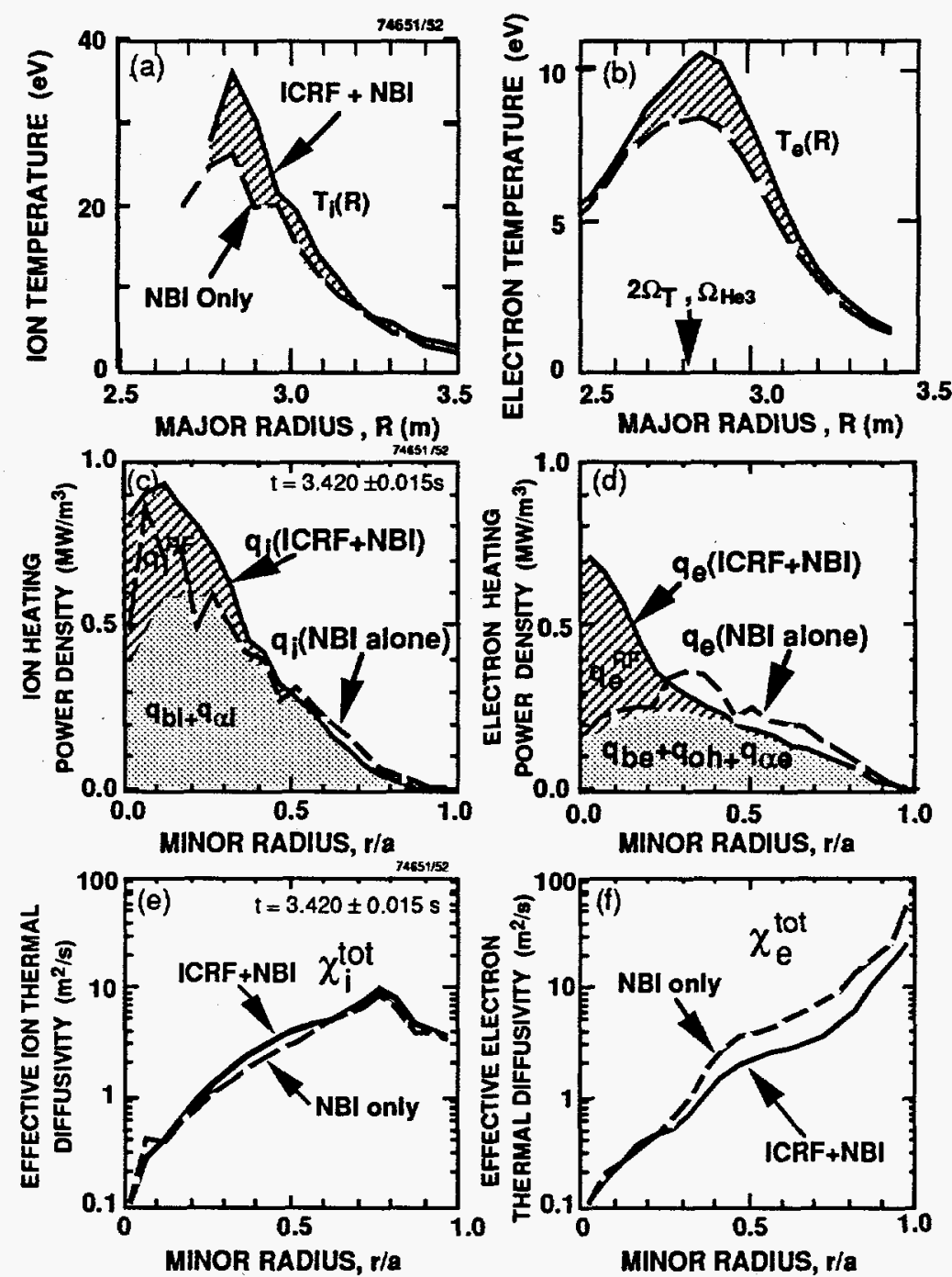

Fig. 3. Comparison of (a) ion and (b) electron temperature profiles; (c) ion and (d) electron heating power density profiles; and (e) ion and (f) electron total effective thermal diffusivity profiles for two plasmas with $23.5 \mathrm{MW}$ of neutral beam injection (60\% in tritium). The plasma indicated by the solid line had $5.5 \mathrm{MW}$ of $43-\mathrm{MHz}$ ICRF heating resonant with the $2 \Omega_{\mathrm{T}}$ cyclotron layer on the magnetic axis at $R=2.82 \mathrm{~m}$. Both plasmas had a $2 \%{ }^{3} \mathrm{He}$ minority, the fundamental resonance of which is degenerate with the $2 \Omega_{\mathrm{T}}$ resonance.

The efficient mode conversion was demonstrated for the first time with plasmas with ${ }^{3} \mathrm{He}$ "minority" ions on TFTR. $[2,4]$ Experiments performed in D-4 ${ }^{4} \mathrm{He}$ plasmas with a high ${ }^{3} \mathrm{He}$ concentration $\left(\mathrm{n}_{3} \mathrm{He} \mathrm{n}_{\mathrm{e}}=15-30 \%\right)$ have demonstrated efficient mode conversion electron heating on and off axis. With the mode conversion layer located on axis and far away from the cyclotron resonance $\left(\Omega_{3} \mathrm{He}\right.$ at $p=0.3$ on the low-field side), highly peaked electron temperature profiles have been observed with central temperatures reaching the 8 to $10 \mathrm{keV}$ range (as measured by Thomson scattering and ECE diagnostics) heated by only 2 to $3 \mathrm{MW}$ of incident if power. The fraction of the power mode converted and coupled to electrons rises with increasing ${ }^{3} \mathrm{He}$ concentration, from 0.2 at $\mathrm{n}_{3} \mathrm{He} / \mathrm{n}_{\mathrm{e}}<10 \%$ (close to the conventional minority heating regime) to $>50 \%$ typical (as high as $80 \%$ ) for $n_{3} \mathrm{He} \mathrm{n}_{\mathrm{e}}=15 \%$ to $30 \%$.
Figure 4 shows the measured major radius of the peak of the electron power deposition profile as a function of the toroidal field for a constant density $\left[n_{e}(0)=4 \times 10^{19} \mathrm{~m}^{3}\right.$ ] and constant ${ }^{3} \mathrm{He}$ fraction (0.14). The power deposition radius is located within a few centimeters of the two-ion hybrid layer $\left(n /\left.\right|^{2}=S\right.$ ) which is separated from the cyclotron resonance $\left(\Omega_{3} \mathrm{He}\right)$ and whose distance from the magnetic axis increases with decreasing magnetic field (i.e., more off-axis).

Figure 5 shows the if heating profile measured by the modulation technique for a discharge in which the mode conversion surface was located at $\mathrm{r} / \mathrm{a} \approx 0.2$ on the highfield side of the magnetic axis. This plasma had a central electron density of $\sim 4 \times 10^{19} \mathrm{~m}^{-3}$, a central electron temperature of $5 \mathrm{keV}$, and profiles that were approximately 


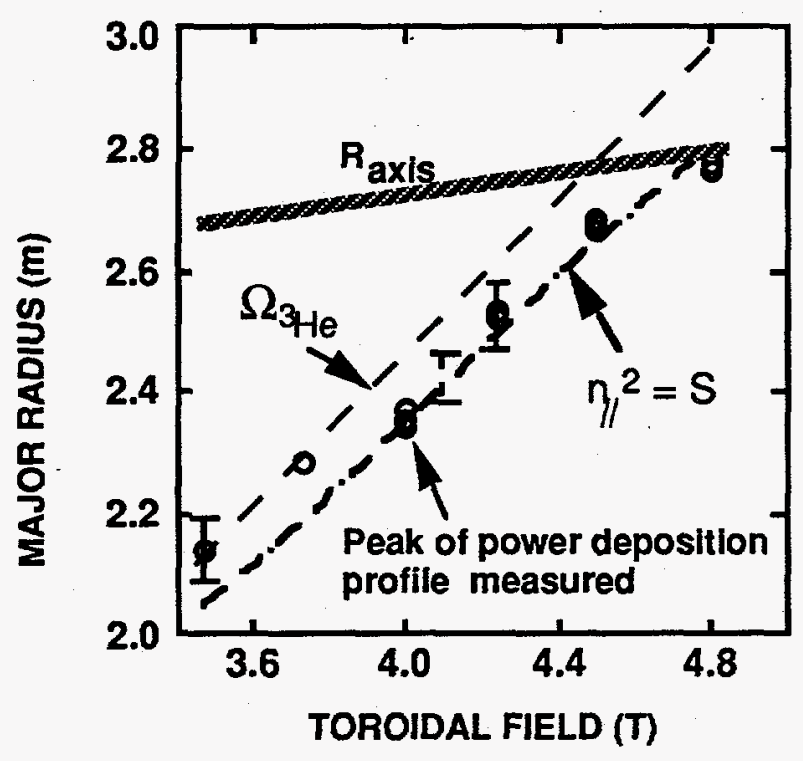

Fig. 4. Dependence of the major radius (open circles) of the peak of electron absorbed power determined by power modulation techniques as a function of toroidal magnetic field intensity for constant ${ }^{3} \mathrm{He}$ fraction $\left(\mathrm{n}_{3} \mathrm{He}_{\mathrm{e}} \mathrm{n}_{\mathrm{e}}=0.14\right.$ ) and constant density $\left(n_{e}(0)=4 \times 10^{19} \mathrm{~m}^{-3}\right)$. The chained line denotes the calculated position of the mode conversion layer, the dashed line the ${ }^{3} \mathrm{He}$ cyclotron layer, and the shaded thick line the approximate position of the magnetic axis in the discharges shown.

parabolic. CHERS measurements from similar discharges imply a central ion temperature of about $4 \mathrm{keV}$ for this plasma. The measured net power coupled to the electrons is observed to be about $70 \%$ of the total if input power,

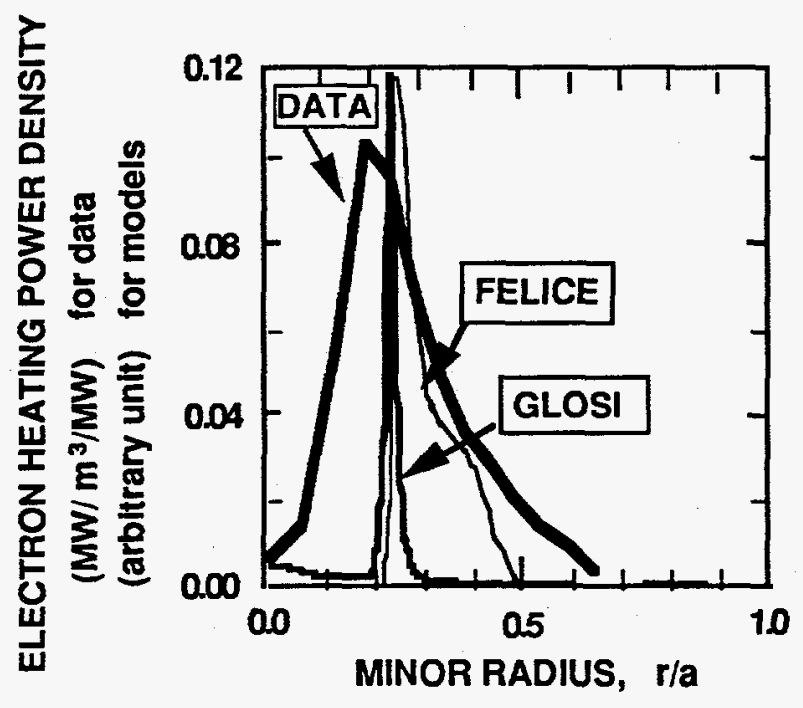

Fig. 5. The ICRF power deposition profile of the electrons, derived from power modulation techniques, is compared with model predictions of 1-D codes (FELICE and GLOSI) for offaxis mode conversion on the high field side of the magnetic axis. with only a small amount, $\sim 5 \%$, deposited near the magnetic axis via direct electron Landau damping. The measured power absorption by electrons is compared with model calculations in Figure 5. The analyses obtained with the 1-D kinetic wave codes, FELICE ${ }^{[15]}$ and GLOSI [16], show good agreement with the observed deposition radius, although the predicted profiles are substantially narrower than the experimental profiles, probably due to neglecting poloidal variations in the equilibrium and wave focusing. The GLOSI code result is based on an average of multiple $k_{\|}$calculations with a power weighting function of a Gaussian form, $\exp \left[-\left(\left(\mathrm{k}_{\|}\right.\right.\right.$ -9)/2 $\left.)^{2}\right]$ to average out the standing wave pattern in the $\mathrm{rf}$ field within the triplet. ${ }^{[3]}$ The FELICE code result is based on multiple (40) toroidal and (5) poloidal modes representing the launched antenna spectrum. The electron absorption fraction predicted by FELICE is $85 \%$ and $82 \%$ by GLOSI.

Crucial to the application of this technique to current drive is the question of directivity of the mode converted IBW. Initial tests were performed in D- ${ }^{4} \mathrm{He}-{ }^{3} \mathrm{He}$ plasmas with $2.2 \mathrm{MW}$ of ICRF power launched with $\pm 90^{\circ}$ antenna phasing to provide a directional fast wave with $\mathrm{k}_{/ / \sim 6 \mathrm{~m}^{-1}}$ at the antenna. The mode conversion layer was placed near the magnetic axis for the If frequency of $43 \mathrm{MHz}, \mathrm{B}_{\mathrm{T}}$ $=4.5 \mathrm{~T}, \eta_{3} \mathrm{He} \sim 12 \%$, and $n_{e}(0)=4 \times 10^{19} \mathrm{~m}^{-3}$. The observed electron temperature response was distinctly different for $+90^{\circ}$ and $-90^{\circ}$ launch. However, the measured surface voltage was essentially the same for these two cases in spite of expectation of rf-driven currents in the range of 100 to $200 \mathrm{kA}$. Subsequent TRANSP modeling indicated that centrally rf-driven currents of this magnitude are insufficient to modify the surface voltage on the time scale of the rf pulse $(0.8 \mathrm{~s})$. Nevertheless, the heating results indicate that the mode converted IBW is directional. Future CD experiments will be performed with longer if pulses and more direct measurements of the current profile by the motional Stark effect.

Off-axis mode conversion electron heating was used to study the inward thermal pinch, transport phenomena that is currently under active discussion for the toroidal confinement research. A strong inward thermal pinch was observed with off-axis electron cyclotron heated $(E C H)$ plasmas in DIII-D.[17] On the other hand, no strong inward pinch was observed in Wendelstein VII-Advanced Stellarator (WVII-AS) ECH off-axis experiments ${ }^{[18]}$, raising the possibility that the strong inward pinch and related the profile resilience are specific to tokamaks. Also during the Toki conference, Dr. Kadomtsev [19] offered an explanation for the phenomena via a trapped particle effect of ECH electrons primarily heated in the perpendicular direction. Since the present heating tends to increase the parallel energy component, it is interesting to see how transport behavior with this heating contrasts 
with that of ECH. Analysis of the electron temperature response at turn-off showed sharp off-axis heating at $\rho=0.24$ with $\Delta_{\rho}(\mathrm{FWHM})$ of 0.17 at $\mathrm{B}_{\mathrm{T}}=4.2 \mathrm{~T}$. Radial variations of the Fourier-transformed electron temperature $\left(\widetilde{T}_{e}\right)$ response (Figure 6) shows that heat pulses propagate simultaneously inward and outward with similar velocities $(\mathrm{d} \phi / \mathrm{dr})$. Furthermore, the thermal diffusivity estimated from the slope of the $\tilde{T}_{e}$ amplitude (on a semi-logarithmic scale) and that from the phase are nearly equal, implying

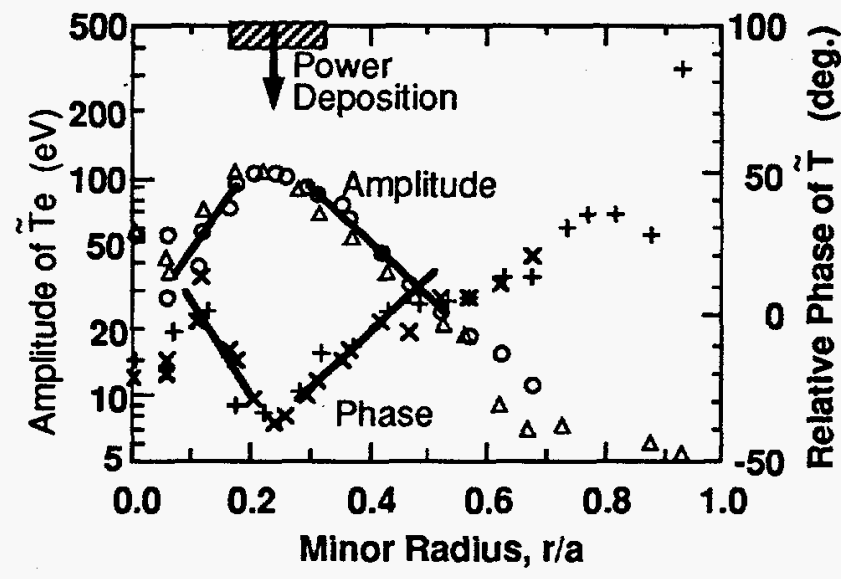

Fig. 6. Dependence of the heat pulse phase (linear scale) and amplitude (semi-logarithmic scale) vs. normalized minor radius for off-axis power deposition with mode conversion electron heating in an $\mathrm{rf}$-heated ${ }^{3} \mathrm{He}-{ }^{4} \mathrm{He}$ plasma. Data are included from two separated ECE diagnostics.

that there is no substantial (inward) thermal pinch.[20] These studies will be extended to rf powers substantially larger than the ohmic power in the future.

\section{CONCLUSIONS}

The first experiments utilizing high-power ICRF to heat D-T plasmas in reactor-relevant regimes have been completed on TFTR. Results from these experiments have demonstrated efficient core, second harmonic tritium heating in D-T supershot plasmas with tritium concentrations ranging from $6 \%-40 \%$. Significant direct ion heating on the order of $60 \%$ of the input rf power has been observed. The measured deposition profiles are in good agreement with 2-D code analyses of these discharges. Based on these observations and models, efficient core $2 \Omega_{\mathrm{T}}$ ICRF heating is anticipated in the higher density plasmas projected for ITER. Energy confinement in an rf-heated supershot is at least similar to that without rf, and possibly better in the electron channel.

Efficient, localized electron heating via mode conversion of incident fast waves to IBWs at the two-ion hybrid layer has been documented with a relatively large concentration of minority ${ }^{3} \mathrm{He}$ ions in D- ${ }^{4} \mathrm{He}$ and D-T.
${ }^{4} \mathrm{He}$ plasmas. By varying the relative concentration of the ion species as well as the toroidal magnetic field for a fixed if frequency of $43 \mathrm{MHz}$, the location of the hybrid layer was scanned between the magnetic axis out to about $40 \%$ of the minor radius on the high-field side of the discharge. The if power modulation studies indicate that $50 \%$ or more of the input ICRF power was damped on electrons near the mode conversion layer, consistent with theoretical predictions. The direction of propagation of the mode converted IBW was shown to depend on the propagation of the launched waves, as controlled by the antenna phasing. Analysis of heat wave propagation with off-axis heating shows no strong inward pinch in ohmically-heated target plasmas in TFTR.

Future TFTR experiments utilizing ICRF heating will focus on both supershot and L-mode regimes (ITER relevant) and increasing the pressure in D-T supershots. We will also explore $\Omega_{\mathrm{D}}$ and mode conversion heating at higher $\mathrm{B} T$ and continue to develop current profile control via mode conversion $\mathrm{CD}$.

\section{ACKNOWLEDGMENTS}

We wish to acknowledge the ICRF group and TFTR project engineering and technical staff for their contribution to this work, and Dr. T. C. Luce of General Atomics for useful discussion. We are grateful to Drs. $R$. Davidson, H. Furth, R. Hawryluk, K. McGuire, D. Meade, and P. Rutherford for their continued support. This research was sponsored by the Office of Fusion Energy, U.S. Department of Energy, under contract DE-AC02-76CHO-3073 with Princeton University and DE-AC0584OR21400 with Martin Marietta Energy Systems, Inc.

\section{REFERENCES}

1. G. Taylor, M. Murakami, H. Adler et al., "ICRF Heating of Deuterium-Tritium Plasmas in TFTR," to be published in Proc. of Fifteenth Int. Conf. on Plasma Phys. and Controlled Nucl. Fusion Res., Seville, September 26-October 1, 1994.

2. C. K. Phillips, M. G. Bell, R. Bell, N. Bretz et al, "Ion Cyclotron Range of Frequencies Heating and Current Drive in Deuterium-Tritium Plasmas," to be published in Phys. Fluids (1994).

3. R. Majeski, C. K. Phillips, and J. R. Wilson, "Electron Heating and Current Drive by Mode Converted Slow Wave," Phys. Rev. Lett. 73, 2204 (1994).

4. R. Majeski, N. L. Fisch, H. Adler, S. Batha et al., "Mode Conversion Studies in TFTR," to be published in Proc. of Fifteenth Int. Conf. on Plasma Phys. and Controlled Nucl. Fusion Res., Seville, September 26October 1, 1994.

5. G. Schilling et al., "Overview of TFTR ICRF Results," Proc. 10th Topical Conf, on RF Power in Plasmas, Boston, AIP Conf. 289, 3 (1993); J. R. 
Wilson et al., to appear in the Proc. of the 18th Symp. on Fusion Tech., Kahlsruhe, Germany (1994).

6. D. J. Grambier, M. P. Evrad, J. Adam et al., "ICRF Power Deposition Profile and Determination of the Electron Thermal Diffusivity by Modulation Experiments in TFTR," Nucl. Fusion 30, 23 (1990).

7. M. Murakami, E. Fredrickson, E. F. Jaeger, D. A. Rasmussen et al., "ICRF Direct Electron Heating Experiments in TFTR," Proc. 20th European Conf. on Controlled Fusion and Plasma Phys., Lisbon, Portugal (EPS), vol. 3, (1993) 981.

8. E. F. Jaeger, D. B. Batchelor and D. C. Stallings, "Influence of Various Physics Phenomena on Fast Wave Current Drive in Tokamaks," Nucl. Fusion 33, (1993) 179.

9. D. N. Smithe et al., "Algorithm for the Calculation of Three-Dimensional ICRF Fields in Tokamak Geometrry," Nucl, Fusion 27, (1987) 1319.

10. G. W. Hammett, "Fast Ion Studies of Ion Cyclotron Heating in the PLT Tokamak," Ph.D. Thesis, Princeton University (1986).

11. D. S. Darrow, S. J. Zweben, R. V. Budny et al., "ICRF-Induced DD Fusion Product Losses in TFTR," PPPL-2975 (Oct. 1994), submitted to Nucl. Fusion.

12. G. Taylor, J. R. Wilson, R. C. Goldfinger, J. C. Hosea et al., "ICRF Heating of TFTR Deuterium Supershot Plasmas in the ${ }^{3} \mathrm{He}$ Minority Regime," Plasma Phys. Control. Fusion 34, 523 (1994).
13. M. H. Redi, M. C. Zarnstorff, R. B. White et al, "Collisional Stochastic Ripple Diffusion of Alpha Particles and Beam Ions on TFTR," PPPL-3011, (1994).

14. Mode conversion is discussed extensively in the review article by D. G. Swanson, "Radio Frequency Heating in the Ion-Cyclotron Range of Frequencies," Phys. Fluids 28, 2645 (1985), and references therein.

15. M. Brambilla and T. Krücken, "Numerical Simulation of Ion Cyclotron Heating of Hot Tokamak Plasmas," Nucl. Fusion 28, 1813 (1988).

16. C. Y. Wang, D. B. Batchelor, M. D. Carter et al., "Effect of Alfven Resonance on Low Frequency Fast Wave Current Drive," to be published as an ORNL Report (1995).

17. T. C. Luce, C. C. Petty, and J. C. de Haas, "Inward Energy Transport in Tokamak Plasmas," Phys. Rev. Lett. 68, 52 (1992).

18. F. Wagner and U. Stroth, "Transport in Toroidal Devices - Experimentalist's View," Plasmas Phys. Control. Fusion 34, 1803 (1992).

19. B. Kadomtsev, "Self Organization and Their Effects on Transport Phenomena," this conference.

20. T. C. Luce, C. B. Forest, M. A. Makowski, W. H. Mayer $e t$ al., "Evidence from Modulated ECH for Convective-like Transport," in Proc. ISPP-14. Piero Caldiorola. on Local Transport Studies in Fusion Plasmas [J. D. Callen, G. Gorini and E. Siodoni (eds.)], SIF, Bologna (1993). 
Dr. F. Paoloni, Univ. of Wollongong, AUSTRALIA

Prof. R.C. Cross, Univ. of Sydney, AUSTRALIA

Plasma Research Lab., Australian Nat. Univ., AUSTRALIA

Prof. I.R. Jones, Flinders Univ, AUSTRALIA

Prof. F. Cap, Inst. for Theoretical Physics, AUSTRIA

Prof. M. Heindler, Institut für Theoretische Physik, AUSTRIA

Prof. M. Goossens, Astronomisch Instituut, BELGIUM

Ecole Royale Militaire, Lab. de Phy. Plasmas, BELGIUM

Commission-European, DG. XII-Fusion Prog., BELGIUM

Prof. R. Bouciqué, Rijksuniversiteit Gent, BELGIUM

Dr. P.H. Sakanaka, Instituto Fisica, BRAZIL

Prof. Dr. I.C. Nascimento, Instituto Fisica, Sao Paulo, BRAZIL Instituto Nacional De Pesquisas Espaciais-INPE, BRAZIL

Documents Office, Atomic Energy of Canada Ltd., CANADA

Ms. M. Morin, CCFWTokamak de Varennes, CANADA

Dr. M.P. Bachynski, MPB Technologies, Inc., CANADA

Dr. H.M. Skarsgard, Univ. of Saskatchewan, CANADA

Prof. J. Teichmann, Univ. of Montreal, CANADA

Prof. S.R. Sreenivasan, Univ. of Calgary, CANADA

Prof. T.W. Johnston, INRS-Energie, CANADA

Dr. R. Bolton, Centre canadien de fusion magnétique, CANADA

Dr. C.R. James, Univ. of Alberta, CANADA

Dr. P. Lukác, Komenského Universzita, CZECHO-SLOVAKIA

The Librarian, Culham Laboratory, ENGLAND

Library, R61, Rutherford Appleton Laboratory, ENGLAND

Mrs. S.A. Hutchinson, JET Library, ENGLAND

Dr. S.C. Sharma, Univ. of South Pacific, FIJI ISLANDS

P. Mähönen, Univ. of Helsinki, FINLAND

Prof. M.N. Bussac, Ecole Polytechnique, FRANCE

C. Mouttet, Lab. de Physique des Milieux lonisés, FRANCE

J. Radet, CEN/CADARACHE - Bat 506, FRANCE

Prof. E. Economou, Univ. of Crete, GREECE

Ms. C. Rinni, Univ. of loannina, GREECE

Preprint Library, Hungarian Academy of Sci., HUNGARY

Dr. B. DasGupta, Saha Inst. of Nuclear Physics, INDIA

Dr. P. Kaw, Inst. for Plasma Research, INDIA

Dr. P. Rosenau, Israel inst. of Technology, ISRAEL

Librarian, International Center for Theo Physics, ITALY

Miss C. De Palo, Associazione EURATOM-ENEA , ITALY

Dr. G. Grosso, Istituto di Fisica del Plasma, ITALY

Prof. G. Rostangni, Istituto Gas lonizzati Del Cnr, ITALY
Dr. H. Yamato, Toshiba Res \& Devel Center, JAPAN

Prof. I. Kawakami, Hiroshima Univ., JAPAN

Prof. K. Nishikawa, Hiroshima Univ., JAPAN

Librarian, Naka Fusion Research Establishment, JAERI, JAPAN

Director, Japan Atomic Energy Research Inst., JAPAN

Prof. S. Itoh, Kyushu Univ., JAPAN

Research Info. Ctr., National Instit. for Fusion Science, JAPAN

Prof. S. Tanaka, Kyoto Univ., JAPAN

Librany, Kyoto Univ., JAPAN

Prof. N. Inoue, Univ. of Tokyo, JAPAN

Secretary, Plasma Section, Electrotechnical Lab., JAPAN

Dr. O. Mitarai, Kumamoto Inst. of Technology, JAPAN

Dr. G.S. Lee, Korea Basic Sci. Ctr., KOREA

J. Hyeon-Sook, Korea Atomic Energy Research Inst., KOREA

D.1. Choi, The Korea Adv. Inst. of Sci. \& Tech., KOREA

Prof. B.S. Liley, Univ. of Waikato, NEW ZEALAND

inst of Physics, Chinese Acad Sci PEOPLE'S REP. OF CHINA

Library, Inst. of Plasma Physics, PEOPLE'S REP. OF CHINA

Tsinghua Univ. Library, PEOPLE'S REPUBLIC OF CHINA

2. Li, S.W. Inst Physics, PEOPLE'S REPUBLIC OF CHINA

Prof. J.A.C. Cabral, Instituto Superior Tecnico, PORTUGAL

Prof. M.A. Hellberg, Univ. of Natal, S. AFRICA

Prof. D.E. Kim, Pohang Inst. of Sci. \& Tech., SO. KOREA

Prof. C.I.E.M.A.T, Fusion Division Library, SPAIN

Dr. L. Stenfio, Univ. of UMEA, SWEDEN

Library, Royal Inst. of Technology, SWEDEN

Prof. H. Wilhelmson, Chalmers Univ. of Tech., SWEDEN

Centre Phys. Des Plasmas, Ecole Polytech, SWITZERLAND

Bibliotheek, Inst. Voor Plasma-Fysica, THE NETHERLANDS

Asst. Prof. Dr. S. Cakir, Middle East Tech. Univ., TURKEY

Dr. V.A. Glukhikh,Sci. Res. Inst. Electrophys.I Apparatus, USSR

Dr. D.D. Ryutov, Siberian Branch of Academy of Sci., USSR

Dr. G.A. Eliseev, I.V. Kurchatov Inst., USSR

Librarian, The Ukr.SSR Academy of Sciences, USSR

Dr. L.M. Kovrizhnykh, Inst. of General Physics, USSR

Kernforschungsanlage GmbH, Zentralbibliothek, W. GERMANY

Bibliothek, Inst. Für Plasmaforschung, W. GERMANY

Prof. K. Schindler, Ruhr-Universitát Bochum, W. GERMANY

Dr. F. Wagner, (ASDEX), Max-Planck-Institut, W. GERMANY

Librarian, Max-Planck-Institut, W. GERMANY 